\title{
The Teacher
}

\section{Beyond the Chalkboard: Multimedia Sources For Instruction in Political Science}

\author{
Carl J. Luna and Joe Mac McKenzie, San Diego Mesa College
}

A new generation of multimedia systems for education have attempted to integrate the more traditional use of lecture and video tape class presentations with programmable personal computer software, video-disc systems, CD-ROMS, and Internet sources with the hope of revolutionizing the ability of educators to integrate lecture, text, and visual images in a comprehensive package. When the "multimedia revolution" (focusing on videotape and, later, laser discs) was first proclaimed in the $1970 \mathrm{~s}$, it was heralded as a panacea for almost every educational ill, from classroom overcrowding to student underachievement. Now, almost a generation later, instructors are still wrestling with how to employ these new teaching tools most effectively. Indeed, after two decades of experimentation, instructors still lack concrete evidence that the pains of learning these new technologies are exceeded by gains in student achievement.

Simply understanding available technology and keeping abreast of new arrivals is a challenge to instructors. Indeed, as instructors in political science have struggled to tame the technological beast, producers of multimedia software have continuously fed the beast "new meat." Five years ago, the paradigm for computer-based multimedia was a laserdisc of text and images indexed and controlled by a PC to project for lecture use. Just a few years ago, CD-

ROMS began to appear, offering the benefit of less equipment and more flexibility: the CD-ROM could be used as a classroom or tutorial tool. Soon, many publishers began offering CD-ROMs to accompany their traditional texts. Over the last year, another "paradigm" shift has gotten underway. The use of "websites" on the Internet has become the new medium of choice. One can only imagine what changes the future will hold in this fast-evolving field.

Recent research has attempted to find the "missing link" between multimedia and student performance in political science courses (Quinn and O'Rourke 1990; Janda 1990 and 1992, Goldman, 1991; Gottleib 1994, Opheim and Stouffer 1995, Luna and McKenzie 1995). While these studies do not categorically demonstrate an empirical link between technology and student achievement, they provide sufficient anecdotal evidence to support the thesis that these approaches to instruction have promise. Indeed, these and other studies (Boykin et al., 1996; Ward, et al. 1996) have reported, student responses to these teaching methods have been overwhelmingly favorable, leading to increased student enthusiasm and participation. It helps to speak the language of the MTV generation.

Early efforts in multimedia involved instructors creating their own computer-based graphical presentations using authoring systems like HyperCard or Toolbook. Quinn and O'Rourke were critical of this approach, pointing out that it required faculty members to invest a great deal of time not only learning the technology, but also inputting data and creating applications. Others have attempted to bring multimedia into the classroom by using "prepackaged" software and CD-ROMs, thus alleviating some of the burden of "re-inventing the wheel." Opheim and Stouffer (1995), for example, report some success in using the
CD-ROM Capitol Hill in introductory courses in American Government. The CD-ROM (reviewed below) provides background text, video, photographs and graphics, as well as a simulation exercise, to supplement traditional classroom lecture and to stimulate class discussion.

The Internet is increasingly an option for integrating electronic technologies creatively into the curriculum. Indeed, at the 1996 APSA Annual Meeting in San Francisco, we discovered that most publishers of multimedia materials are already moving away from CD-ROMs to Websites. The golden days of the CD-ROM were apparently short and not-so-sweet. The trend has made it to political science. Gottlieb (1994) discussed a three-year class project in on-line networking to support a class in environmental politics. He reported that the technology offers advantages in terms of increasing student interest and motivation in course work. It also faces major hurdles that need to be surmounted to use this material effectively in the classroom, including mounting the steep learning curve of the technology itself, as well as the material problems of finding enough equipment and access time for students along with sufficient technical support staff to make the equipment function smoothly.

For all the challenges presented by these new technologies, they still offer the promise of helping students learn better. This is not to argue that "the machine" will replace the professor as the principle vehicle of learning; far from it. These tools amount to an attempt to improve the primary tools of education: the chalkboard and the text book. Any 
tool, of course, will only be as good as the artisan that uses it. As Opheim and Stouffer state, while such technologies "will not replace a well-planned and insightful lecture," it can, however, "provide an insightful supplement to traditional teaching strategies."

This article is based on a survey of numerous text and media publishing houses and on-line providers known to provide titles in political science. Our review is not exhaustive, as new titles are entering the marketplace monthly. Rather, we seek to provide a cross-section of different approaches and materials attempting to integrate multimedia technology into the political science curriculum. The remainder of this essay looks at a cross-section of materials currently or soon to be available in political science, divided into three categories: laserdisc, multimedia/CD-ROM, and on-line sources.

\section{Laserdisc}

Through the 1980s, advanced multimedia by definition meant a laserdisc full of images and audio tied into a computer or laserdisc playback unit. The greater flexibility and amount of information offered by CD-ROMs and the Internet, coupled with the unwieldy nature of the computer/laserdisc system has rendered this multimedia format somewhat obsolete, even though it is capable of providing superior video quality. Still, publishers release the occasional laserdisc, usually in support of existing texts.

One example of such a laserdisc is American Government Lecture Launchers (W.W. Norton \& Company, 1994) designed to accompany the textbook American Government: Freedom and Power (Lowi and Ginsberg 1994). The still image quality and the digitalized sound on this disc are excellent. The motion video, however, are less clear. The disk consists essentially of lectures given by Professors Lowi and Ginsberg to support each chapter of the text using a team teaching approach with few graphical elements. What normally makes the team teaching useful to students is their ability to ask each professor questions, and vice-a- versa. Team teaching on laserdisc, lacking in interactivity and visual stimulation, reduces it to an exercise in passive listening; student attention will undoubtedly drift.

The Politics in Action (Harper Collins, 1995) disc is visually stimulating. For the first minute of each section of material the viewer is treated to a fabulous MTVesque musical introduction with attention grabbing visual images. However, the basic structure of each of the sections is what might be called a "clubsandwich" approach: a slice of video followed by a slice of still photos followed by another slice of video, all with a sound-bite variety, voiceover narration. While we cannot predict the effectiveness of this technique, our experience with video tape indicates that students' attention span will shorten at this point. From a technical perspective, however, it is much easier to navigate through a laserdisc than it is through videotape, especially when it is inte-

\section{It helps to speak the language of the MTV generation.}

grated with either bar coding or PC software for automated indexing. For instance, both West's American Government Videodisc (West 1994) and Lecture Launcher discs are designed to operate in conjunction with bar code readers or with West's Lecture Launcher Software (1.0). This allows the flexibility to customize lectures using a variety of still and motion clips. Indeed, this provides for the most flexible and personalized videodisc format we have seen. The American Government disc follows the same general format as those above, using short video clips (2-5 minutes) to underscore major points. It also uses a number of still graphics (charts, tables, maps) and fifty minutes of short video clips drawn from PBS programs like Bill Moyer's "In Search of the Constitution" together with historical reenactments.

Interest Groups and the Power of
PACS Level III Videodisc (West, 1994) and American Government: Roots and Reforms Videodisc (Allyn and Bacon, 1995) take existing video, audio, textual, and graphical elements from other sources (video tape version of a telecourse in the former case, and CNN news footage in the latter) to supplement their companion textbooks. The production quality of the discs is very good, with high resolution video images and high quality audio. On the other hand, the videodiscs themselves provide little apparent advantage over the original videotape presentation, despite the trade off of greater hardware costs to the user.

Videodisc technology promised to make it easier to manipulate and sort information for presentation than using videotape. These presentations are of a higher visual quality than those possible with chalk board and overhead projector alone. On the other hand, from a practical perspective, this whole genre of multi-media has limitations. The cost and complexity of acquiring and maintaining the required hardware systems seems to outweigh the increased benefit from using videodiscs. Videotape technology is cheaper and already universally available. Moreover, the rigid chapter-based format of most discs, being translated directly from the textbooks is as constrained as a regular textbook, lacking "hyper"-media/ interactive quality. One is left with the question, "Why bother?"

\section{CD-ROM}

CD-ROMS have been hyped as providing the solution to the limitations of videodiscs. They require less equipment (CD-ROMs now being a standard feature on PCs), they provide more information and are more easily manipulated, and they offer a better potential for direct student interactivity. We have reviewed a number of recent CD-ROMs for political science, which ranged in scope from digitalized databases to reasonable approximations of full multimedia. For a brief period, these titles represented the cutting edge of electronic media in political science. They also demonstrate the technical 
limitations that need to be overcome to make this technology truly dynamic. While a few of these discs are suitable for comparative politics and international relations, most of these resources focus on the field of American government, usually at the introductory level.

For instance, the American Government CD-ROM (Brown \& Benchmark Publishers, 1994) provides all of the elements of true multimedia: motion video, audio, still photos, graphics, animation, and hypertext. Based on the text American Government: The Political Game by Stephen Frantzich, this disk uses a standardized screen format in which text boxes and menu selections are presented on the right side, photos and video windows with icon controls on the left. The user scrolls through a table of contents menu to select sections of text for review. Essentially, the content simply duplicates the original book. Sections contain both extensive text boxes, photos, and graphics. The user has multiple routes of navigation; by text menu, hypertext "hot words," pull down menu, and icon. Some chapters contain quick time video drawn largely from historical archival footage, such as Martin Luther King's "I Have a Dream" speech. Some chapters also contain case studies and short simulation games in pop-up dialogue boxes designed to underline key concepts. These multimedia elements are provided in support of the text box material, which is the real focus of the presentation. This CD-ROM is a good attempt at a multimedia presentation limited by the current state of technical development. The still photos, audio, and graphics are of high quality. The Quick time video format, while solving some of the storage capacity problems of full motion, gives the presentation a vintage kinetoscope ambience: it is 1900 , and film making is not quite down pat yet.

American Government and Politics Today: 1995-1996 Interactive CDROM Edition (West, 1995) was also developed for use with a conventional text, in this case West's American Government and Politics Today (1993). The CD-ROM we reviewed contained only a demonstration module consisting of "Chapter 5:
Civil Rights," limiting our ability to form a developed opinion of the product. The hard cover text and CD-ROM versions, like Brown \& Benchmark's American Government $C D-R O M$, contain the same chapter organization and materials. For instance Chapter 5 of both versions begins with a section entitled "What if we had unrestricted immigration?" In the book version, the reader is presented with text and accompanying photos or short informational boxes in the style of USA Today. In the CD-ROM version, the photo is replaced by a short quick-time video clip with sound on unrestricted immigration, thus giving a more dynamic presentation which draws the visually-oriented student into the lesson. Indeed, this presentation used more video clips than any other we reviewed.

Each page presents text on the right side of the screen and a box for still photos, video clips, charts, and graphics on the left. The text is highlighted by hot words which tie the users to dialogue boxes defining the words. The program offers additional interactive features. The first is an on-line personal notebook allowing students to type in notes as they use the presentation. Secondly, the program provides a quiz-cards option, allowing the student to type information for flash-card style review. Thirdly, each chapter concludes with a set of remediation questions (multiple choice, true false, identification, short answer) for self-drill. The remediation module keeps track of self-test results and directs the students where to look back in the text for review. Indeed, the remediation module of this disc was the most developed we have seen. Fourthly, the disc has a presentation maker allowing the user to reorganize the CD-ROM material. Dialogue boxes scattered through the presentation identify key topics. The program even provides the student with lists of internet addresses creating opportunities for pursuing additional study. The program contains a graphic interactive time line from 1610 to the present which allows students to locate key events, court cases, demographic information, presidential administrations, and major legislative acts. We found this feature particularly effective.

This CD-ROM was more cleanly organized than many of the others we reviewed, with easier navigation and hyper-connectivity, lots of quick motion video, and good use of colors. One of the disc's disadvantages was its lack of speed. We first tried to run the program on an IBM 486 multimedia platform without success. We then successfully ran the program on a Powermac 7100/66, a reasonably fast machine. However, it still took a full minute to present the graphical time line and another thirty seconds to return to the main program. Going from page to page and feature to feature was also slow. The speed of presentation is critical for multimedia methodology because the slower the speed, the shorter the attention span of today's Nintendo joystick-trained student. The dialogue boxes present Spanish translations of key terms, but had no voiceover Spanish translation, making this feature somewhat irrelevant. This disc essentially carries out the complete paradigm of CD-ROM as electronic book, replacing traditional still photos with motion/animation.

Publishers are increasingly publishing their materials in multiple medias as well. It has become fairly traditional to now see a work released as a classic printed text, with software, a laserdisc, and a CDROM as supplements. American Government (Allyn \& Bacon, 1995) is such an example. Like their corresponding Videodisc, this CD-ROM was developed to accompany Allyn and Bacon's text American Government: Roots and Reforms by O'Connor \& Sabato. Since the disc is not yet completed, we reviewed a demonstration module containing only a portion of the features promised for the final disc. This disc is, on the one hand, the weakest we looked at in terms of content. At the same time, it is probably the best disc in terms of being a potential paradigm. Instead of a page-through book format, this multimedia template is more like an old-style 1950's jukebox where you can select any one of a series of two minute informational "tunes". The user is first presented with a map of Washington, D.C. overlayed with four "points 
of interest" that can be clicked on for information. (For the demo disc only the "Congress" was functional; the "Presidency", "Judiciary," and "America On-line" modules were not.) Each "lesson" consists of short boxes of informational text and an accompanying still photograph. The user's navigational options are limited to simply paging sequentially through the text offerings or returning to the main menu, which offers no real "hyper-connectivity". The text offerings themselves are presented at a relatively rudimentary level. The graphics were difficult to read even using the provided "magnify" option). Combined with the absence of motion-video and any audio, the disc, at least at this stage of development, would probably try the patience and interest of average students.

The limited amount of content in this disc works to its advantage, however. Presenting small, easily digestible pieces of information might well contribute more to student retention better than the hitthem-with-everything-you've-got approach used by the other discs we reviewed. Informational overkill, while a delight to the professors who design and might use these discs, is almost certain to drive non-professional users to distraction. We could see ourselves spending hours peering into all of a disc's nooks and crannies, but realistically, we can't see our students doing the same. The Allyn and Bacon disc fits more into the mold of multi-media as "hyper cliff notes"-in and of itself not a replacement for lecture and texts, but a reasonable supplement to more traditional forms of instruction. We believe this may well be a better paradigm for multimedia instruction.

Not all CD-ROM packages adhere to the rigid texts and graphics format. Harcourt Brace has designed its upcoming release $C D-R O M$ For American Government as a "standalone" tutorial package for students. While designed to be used in conjunction with a standard text, it is not designed as part of a particular text. The disc consists of interactive lessons consisting of text, audio, graphics, and video clips on the major topics covered in a traditional introduction to American government class. The disc offers instant remediation through quizzes and other features to allow students to more easily customize the presentation to their learning needs. McGraw Hill's Hypergraphics $C D$ $R O M$, issued in conjunction with The American Democracy textbook by Patterson, spices up the usual mix of text and graphics with review questions, survey research data, and a "Jeopardy"-style review game. The disc can be used in conjunction with a interactive lecture-based presentation package, complete with hand held response pads that allow students to record answers to questions or votes.

A number of CD-ROMs applicable to political science are emerging from sources other than traditional textbooks. For instance, The Clinton Health Security Plan (Allegro New Media 1994) was used a CD-ROM to package information about a current political debate. This disc provides a comprehensive record and advocacy of the Clinton health care initiative. Included on the disc are the audio and video of the President's health care address to Congress and the entire text of the administration's complete legislative proposal. Commentary from a variety of public figures in support of the plan is also included. Users can navigate easily between sections using simple text menus, hot words and pull-down menus. The format of the presentation is much like that in the American Government $C D-R O M$, with each "page" divided between text and video boxes. Unlike the former, however, the text is provided in accompaniment of the visual and audio elements. Moreover, the disc is not directly dependent upon an outside text. Of all the CDs we looked at, in terms of visual effects this one came closest to a full multimedia presentation. It has excellent color-still graphics, quick time video, a very good index, and easy menu navigation. The presentation has a well-developed structure which seamlessly propels the user towards the goal of understanding its content. This disc also represents a political innovation: the first use of CD-ROM technology we are aware of that sought to directly influence public opinion on a policy issue. Here we have a high-tech solution to promoting understanding of complex political processes; public debate on CD-ROM. The CD-ROM makes no effort at scholarly objectivity; its sole purpose is to promote support for a particular political program. The narrowness of the presentation's focus, however, is a weakness. We have here an exhaustive exposition on the Clinton Health Care Plan, perhaps the best explanation of this extremely complex issue ever produced in the popular culture. But for most educational purposes this limited focus compromises the costeffectiveness of institutional use, leaving it primarily as a research source. Given the fate of the legislation, the disc may now be irrelevant.

Political Risk Services On CDROM (Advanced Multimedia, updated annually) provides data on one hundred nations, including extensive political, economic and demographic information, and assessments of political stability and turmoil in eighteen month and five year time frames. Although not true multimedia, we found this to be one of the most useful discs we have seen; a vast amount of information is very conveniently packaged and cross-referenced, allowing true ease of navigation. The writing style is concise and vigorous; textual expositions are limited to approximately one paragraph per topic and interspersed with graphs and tables to add visual data to the thematic presentation. The information was up to date, while covering a wide range of countries. This disc is useful both to business professionals seeking to create foreign operations in growing international markets and to undergraduate and graduate instructors.

Quanta Press is a prolific producer of CD-ROMs with application to political science. Each Quanta product operates on the same principle: each contains a large data base with automated search and retrieval functions. The user is prompted to enter a term relevant to the database. The database is then searched for all records containing that term, which are then displayed to the user. These CD-ROMS provide a wealth of useful information, but are difficult to navigate. For example, in Terrorist 
Profiles there are 5,905 unique words in 75 record cards. But the program lacks a simple menu system that would allow the novice to select terms for searching the database. The existing index facility is not readily identified by accompanying manuals (we discovered it accidentally by typing the word "index" at the search prompt). These discs tend to be useful only for users with professional-calibre knowledge, such as journalists and graduate researchers. All of the Quanta products are dualformatted for MAC and IBM and easily installed and run. IBM users require $\mathrm{PC} 386$ or higher, 512K RAM, MS-DOS 2.0 or higher, and CD-ROM extensions.

CIA World Fact Book (Updated annually) is a digitalized "almanac," providing data on 264 countries and territories. Areas covered include type of government, major political figures, vital statistics, population demographics, geography, economic data, major political disputes, demographic and geographic data, and economic indicators. The source for the disc's data was public domain information gathered from a number of government agencies, including the Central Intelligence Agency, the Bureau of the Census, the Defense Intelligence Agency, and the Department of State. Using any of approximately 30,000 key words, the user may search almost 1,600 records for relevant matches. Heavy on facts, but weak on analysis, this disc provides a good reference source for undergraduate instruction, research and business. Quanta's $K G B$ World Fact Book (1992) is designed along the same format as the CLA World Fact Book, providing the same types of information as the former, but from a different perspective. Information for this disc was assembled from public archival sources of institutions of the former Soviet Union. In this case, data is presented on 249 countries and territories.

The Middle East Diary (1990) database was developed from public government sources, including U.S. State Department Background Notes, documentation on treaties, U.S. Department of Travel Advisories, and the Central Intelligence Agency. The documents and records culled from these sources are used to provide data presented in textual narrations on nations, organizations, political leadership, individuals, and political processes in this region. The database may be searched using almost 24,000 key words to search its thousand records. The graphics contained on the disc include color country flags and black and white country maps. Quanta also produces a similar disc, Terrorist Group Profiles (Quanta, 1991). This CD-ROM contains information in 75 records accessible through 6,000 key words on dozens of internationally known terrorist groups. The database provides statistics, chronological histories, leadership, membership, sponsors, objectives, targets, and geographic area data on terrorist groups around the globe.

Quanta's Vietnam Remembered (1992) provides an electronic database of recollections provided by Vietnam vets, this digital oral history includes black and white photos and text to provide a behind-the-scenes look at the Vietnam conflict. The data is divided into fifteen categories, such as bibliography, chronology of the conflict, and statistics.

Quanta's U.S. Civics: Federal Citizenship Tests (1993) disc is based on the U.S. Immigration and Naturalization Service's "Federal Citizenship Tests." The 168 records of the database contains information on historical events, government structure, and selected biographies. References are accessible through 6,396 key words. While the material contained on the disc is relatively remedial, it could provide a potential resource for introductory course on American government.

Chadwyck-Healey, a British publisher, provides a number of useful titles for students of comparative politics an international relations. These includes the House of Commons Hansard on CD-ROM and House of Lords Hansard on CD$R O M$, the complete digitalized record of all proceedings for both houses taken from the definitive biweekly Hansard; UNBIS Plus, a search database for documents and publications of the United Nations; and EUROCAT and OJindex $C D$, which provide a similar database on the European Union and the Official Journal of the European Union.
Analytical statistical packages, which were once the mainstay of computer assisted instruction in political science, have also joined the CD-ROM migration. For example, MicroCase Corporation has issued its American Survey on CD-ROM. Like its predecessor software packages, the disc allows students to conduct a variety of survey research with a proven database.

In addition to the CD-ROMs detailed above, there are a number of other titles currently available which may be helpful to political science instructors. We cannot vouch for the quality of these products, but present them for reader edification.

The ' 92 Vote (ABC News Interactive, 1993): Billed as a multimedia magazine, the disc integrates one hour video ( $\mathrm{ABC}$ news footage) and supplemental audio with dozens of photos and narrative text. One should note that the time lag found in producing conventional texts on current events is also found in electronic media. Indeed, given the intense manhour requirements of even modest multi-media efforts, this "event time to print time" lag may prove even greater in this area.

American Government Multimedia Study Guide and American Govemment Simulation Games (Prentice Hall, 1994): Developed by G. David Garson of North Carolina State University, these two products are student supplements for Prentice Hall's Government By the People (16th edition). The study guide provides students with text, video, simulations and other material to support an introductory course in American government. The second disc provides seven simulation exercises to engage the student in role-playing situations on the Congress, foreign policy, and domestic issues.

Capitol Hill (Software Toolworks, 1994): This interactive simulation provides the user with an "insider's tour" of the Federal Capitol Building. The user participates in swearing-in ceremonies of new members of Congress and follows the process by which a bill becomes a law. The simulation includes 45 minutes of video clips and nearly 500 photos, plus audio narration and music.

Clinton: Portrait of Victory (TimeWarner Interactive, 1993): A "be- 
hind the scenes" examination of Clinton's 1992 victory, the disc uses more than 300 still photos, text and audio of speeches, audio narration, and music.

Desert Storm: The War In the Persian Gulf (Time-Warner Interactive, 1993): A compendium of text and multimedia elements, the disc provides an archive of original unedited correspondent reports indexed chronologically and by subject, as well as a glossary of terms. Audio reports from the reporters of Time Magazine, more than 300 photos, text of filed stories, and an active timeline are integrated to supplement the written text which forms the core of the presentation.

\section{On-Line}

If CD-ROM is the current stateof-the-art, on-line sources are most assuredly the future. We were, at first, "doubting Thomases" as to the efficacy of computer networking, but our first few sessions on-line made us into believers. There is simply no way, in our opinion, pre-packaged distribution electronic media can, even in the near term, provide the variety and depth of information available on-line. The difference here is comparable to that between access to one shelf of Walden Books versus the entire Library of Congress. It should be a national priority that all educational institutions, and eventually all educators and students receive network access.

There are numerous good books on using the Internet, such as The Internet Guide for New Users (Dern, 1993), The PC Internet Tour Guide: Cruising the Internet the Easy Way (Fraase 1994), and The Whole Internet: User's Guide and Catalog (Kroll, 1994). There are also several good guides tailored to practitioners of political science. We recommend The Houghton Mifflin Guide to the Internet for Political Science (1995) by Cecilia G. Manrique, University of Wisconsin. This text is an invaluable aid to political scientists anxious to "surf the Net." Besides providing instructions for accessing the Net and using e-mail, the guide provides a discussion of different on-line systems for accessing information through systems like Gopher Servers, Telnet, and World Wide Web (WWW), and gives some examples and addresses of different internet sources related to political science. Prentice Hall is currently packaging another guide, Political Science on the Internet by Andrew T. Stull and James Puetz, with its textbooks. In addition to a basic introduction to the Internet, the guide provides simple instructions for constructing a web page, and it provides a listing of 40 websites related to political science, ranging from comprehensive listings of U.S. Federal agencies to the major parties' home pages.

Government Online by Max Lent (Harper Collins) provides a handy directory to numerous Internet sites. The only problem with these guides is their inability to remain current; sites simply spring up and change too quickly for any print media to stay abreast.

The Internet allows the user to join numerous discussion groups relating to political topics, and, more significantly, provides access to extensive databases applicable to applied research. There are numerous opportunities for integrating the Internet into the political science curriculum (Manrique, 1996), including use of e-mail for greater instructor/ student contact, on-line chatrooms for political discussion, on-line databases for student and faculty research, and on-line networking for political organization and public mobilization. The costs of learning and becoming proficient in on-line navigation are well worthwhile. There are literally hundreds of different sources currently available on-line which may be of interest to the political science practitioner. These include libraries and databases for local, state, national and international governments, universities, and professional organizations. Some of these sources provide gateways to storehouses of information in their areas; others provide detailed documentation of particular issues, while still others provide open bulletin board facilities for dialogues. In each case, they support functions inherent in both research and instruction in political science. Stull (1996) provides a good rule of thumb for browsing the Net: start your search at major government, university, and library websites, as these usually have the best links to additional resources.

Here are a few of the more interesting sources we have used along with their addresses. These sources serve the research and communication needs of the entire range of users, from introductory level undergraduates to post-graduate professionals.

1996 Human Rights Report by Country (State Department) (gopher:// cyfer.esusda.gov/11/ace/state/hrcr). The complete text of the 1994 HRR covering the globe is made easily accessible on-line. Five appendices of related documentation are also provided in addition to the national reports. The file on Brazil alone ran 41 pages.

CLA World Fact Book (http:// gnn.com./gnn/wic/reFbook.02.html). The same information available on the "static" medium DR-ROM version, this on-line source provides updated statistical textual data on numerous nations and regions. This demonstrates a clear advantage of on-line sources: a continually revised database with open access.

Congressional Quarterly (gopher:// gopher.cqalert.com). $C Q$ on-line provides the same services available from its printed counterpart. The site includes analyses of major issues drawn from $C Q$ Quarterly Weekly and Special Reports, reports on current events from the $C Q$ Researcher, perspectives on state and local government from Governing Magazine, and information on books, seminars, and other publications and services, plus e-mail directory listings. Users may access both current and archival $C Q$ data files which may be downloaded to the users system.

The World Wide Web Virtual Library of State Government (http:// gnn.com./gnn/wic/state.01.html). This source provides comprehensive access to government databases for all fifty states, including information on legislative activity (calendars, pending bills, committee sessions) bureaucratic actions (hearings, published rules) and other areas of government activity.

United Nations Gopher (http:// gnn.com./gnn/wic/govt.29.html). The UN gopher provides access to a 
number of different data bases covering the history and structure of the organization, as well as on its current programs and agenda and actions of its main organs.

International Government Resources Gopher (http://gnn.com./gnn/ wic/govt. $45 . \mathrm{html}$ ). The user can access a large collection of search gophers linked to the United Nations, NATO, and other international organizations and resource databases. The gopher is maintained by the Marvel Services of the United States Library of Congress. As of this writing the gopher contained over thirty subdirectories for sources like the International Monetary Fund (IMF) and the General Agreement on Tariffs and Trade (GATT). For example, the International Monetary Fund subdirectory provides access to background information and the history of the IMF, conference listings, and indexes of country reports, analyses, and other papers published by the organization which may be obtained for a fee.

Yahoo Index of Government by Country (http://gnn.com./gnn/wic/ govt.41.html). Like the Library of State Governments, this service links the user to an index of dozens of international databases. Accessing "CANADA" ties the user into its Federal Government Data Base, in which information on anything ranging from fisheries policies to the current Canadian Federal Budget may be downloaded. Under the "NETHERLANDS" we recently accessed the home page maintained by the Dutch Labor Party, with information on its history and current legislative agenda, as well as data and analysis on recent parliamentary elections. The Dutch Party even provided access to an on-line "beer party" where the political issues of the day are discussed.

1996 Proposed Federal Budget (http://gnn.com./gnn/wic/ govt.27.html). The entire federal budget is made easily accessible in this comprehensive searchable database. Included is the complete text of the President's budget message, background analyses, and the full text of the Federal budget by agency and department, right down to the transportation budget for the Chief Justice of the Supreme Court.
State Department Travel Warnings and Consular Information Sheets (http://gnn.com./gnn/wic/ govt.10.html). This source provides regularly updated basic background (demographics, government, etc.) on most nations in the world and the status of current U.S. policies towards them.

Supreme Court Rulings (http:// www.law.cornell.edu.supct/). All Supreme Court opinions and decisions from 1989 to the present are contained in this indexed and searchable database maintained, in part, by Cornell University. Users may search the database by parties or topic, and access background information on the case, the full text of the decision and majority opinion, and the full text of all concurring and dissenting opinions. New decisions are posted to the database immediately upon

\section{Political science}

\section{practitioners should be}

aware of the wealth of opportunity that currently exits in electronic media

\section{applicable to their}

discipline.

release, making this source far more current than any printed medium. Hence, last year we were immediately able to review the decision and opinions for the recent historic decision in United States vs. Lopez.

Political Science Resource (http:// www.keele.ac.uk/depts/po/psr.htm). This web page offers a index of useful sources for the political science practitioner, including collections of documents, treaties and declarations maintained by sources such as the CIA, White House, and the U.S. House and Senate. The index includes sources on elections and electoral systems, political parties and interest groups, political thought, international relations, area studies, and more. Research specific sources are included, such as access to the web home pages of selected journals and newspapers, and other political science gopher servers.

The Electronic Hallway for Policy and Leadership Exchange (http/l cases.pubaf.washington.edu/Oc: abouthtm $/ /$ ). This site provides an on-line case study system for use in public administration and public affairs courses. Developed by the Public Service Curriculum exchange, the "Hallway" provides access to the JFK School Case Studies program, as well as additional teaching modules and policy cases. As of August, 1996 , fees will be charged on an institutional basis for its use.

Websites are becoming more sophisticated, mimicking the slicker, broad audience presentation style of the major traditional newspapers and magazines. On example of this is PoliticsNow Classroom (website currently under construction), a joint venture of PoliticsNow, an existing on-line website publication, and Houghton Mifflin, slated to be operational in the Fall of 1996. The online service, to be packaged for an additional fee in conjunction with a traditional text, will allow students access to a customized news service on political events, complete with headlines and analysis, live interviews with political figures, and student and faculty chatrooms. We had a chance to see the current conceptual framework at a recent demonstration. Each week or month, in correlation to the usual progression through the syllabi for an introduction to American government course, PoliticsNow Classroom would post a collection of articles, interviews and sources related to the syllabi contents. Most introductory American government courses begin with the Constitution, then progress through Federalism to political participation. In September, then PoliticsNow would focus on constitutional news and analysis; in October, it might be current articles on Washington and the states, and so forth. We found the approach intriguing, but with some limitations, as not all courses adhere to the exact same timetable, complicating access to timely material.

McGraw-Hill is developing a website to supplement the American Democracy text. Scheduled to debut in October, 1996, the site will provide 
e-mail connections to the text's author, Tom Patterson, and links to current news and political sources, including access to different simulations and exercises on American government. The website will include a "Professor's Corner" for instructors use, and a "Back Fence" chatroom for students to post messages about current political debate. The hope here is to expand education beyond the individual classroom; to establish a "national" classroom with a broader, richer exchange of ideas.

The American Political Science Association (www.apsanet.org) is also on-line, offering information about conferences, membership events, and research opportunities. There are a number of different sources for grant and research support, and foreign educational opportunities as well.

A word of warning is in order: there is so much available on the Net that the venture can become a waste of your precious time. You drift mesmerized from gopher to gopher, file to file, as the clock spins 'round. Next thing you know, you've lost forty-five minutes looking at the "X-Files" or "Simpsons" home page, while your in-basket piles up.

\section{Conclusions}

Political science practitioners should be aware of the wealth of opportunity that currently exits in electronic media applicable to their discipline. The sheer quantity of data available in CD-ROMs and especially on-line, presents an unparalleled tool for research and the dissemination of ideas within the academic community. But all multimedia users should be aware of potential limitations before they establish a CD-ROM or internet requirement for their curriculum.

CD-ROMS are more dynamic, but traditional books are cheaper and easier to use. There are literally thousands of current political science books available to instructors and libraries, for instance; in contrast, there are only a few dozen CDROM and software titles available. Indeed, as we reviewed different titles, it became apparent that current efforts in multimedia development may well be pursuing the wrong par- adigm: multimedia as electronic book. Conventional books work just fine at what they do, and have for centuries, presenting text and images in a fixed, sequential fashion. A true hypermedia, however, must approach the delivery of information differently than standard texts, as delivery of the written word differed from the oral tradition it supplanted. CD-ROMS seem too ingrained in the text paradigm. The Internet is still an untamed frontier of boundless information with little structure. Alas, that the chalkboard remains, hopefully for only the near term, as the instructors best friend.

\section{References}

\section{Multimedia and Education}

Boykin, Milton L., Terry Mays and Marjie T. Britz. 1996. "Teaching Effectiveness of Computers and Multimedia Applications." Paper presented at the American Political Science Association Annual Meeting, San Francisco, CA.

Goldman, Jerry. 1991. "A Hypercard Tour of the American Judiciary," Paper presented at the American Political Science Association Annual Meeting, Washington D.C.

Gottlieb, Joel. 1994. "Online Networking and the Teaching of Environmental Politics." Paper delivered to the Western Political Science Association 1994 Annual Meeting, Albuquerque, New Mexico, March 10-12.

Janda, K. 1990. "Theory of the Laser Class: Using Video Disc." Paper delivered at the American Political Science Association Annual Meeting, San Francisco.

Janda, K. 1992. "Multimedia in Political Science: Sobering Lessons From a Teaching Experiment." Journal of Educational Multimedia and Hypermedia 1:341-354.

Luna, Carl and Joe Mckenzie. 1994. With J. McKenzie. "Application of Multimedia and Interactive Video Technologies to the Political Science Curriculum." Paper delivered to the Western Political Science Association 1994 Annual Meeting, Albuquerque, New Mexico, March 10-12.

Luna, Carl and Joe McKenzie. 1995. "Electronic Media for Political Science: Waiting for the Model T Ford." Choice 33 (September):49-58.

Manrique, Cecilia. 1996. "Using Netscape in the Political Science Classroom." Paper presented at the American Political Science Association Annual Meeting, San Francisco, August 31-September 3, 1996. Opheim, Cynthia and W. B. Stouffer. 1995. "Using 'Capitol-Hill' CD-ROM To Teach Undergraduate Political Science Courses." Paper presented at the American Political Science Association Annual Meeting, San Francisco, August 31-September 3, 1996.

Quinn, Kathleen M. and John J. O'Rourke. 1990. "The development of Interactive
Computer Learning Aids Using Hypercard in Teaching World Politics". Paper presented at the American Political Science Association Annual Meeting, San Francisco.

Ward, Art, et al. 1996. "Multimedia in the Political Science Classroom: Smoke and Mirrors or a Legitimate New Pedagogy?" Paper presented at the American Political Science Association Annual Meeting, San Francisco, CA.

Weisberg H. F. and L. V. Hennessy III. 1991. "Teaching Data Analysis in an Interactive Environment." PS: Political Science and Politics 24 (September):505-510.

\section{Internet Resources}

Dern, Daniel. 1993. The Internet Guide for New Users. NY: McGraw-Hill.

Fraase, Michael. 1994. The PC Internet Tour Guide: Cruising the Internet the Easy Way. Chapel Hill: Venta Press.

Krol, Ed. 1994. The Whole Internet: User's Guide and Catalog 2nd ed. California: O'Reilly \& Associates.

Manrique, Cecilia G. 1995. The Houghton Mifflin Guide to the Internet for Political Science. Boston: Houghton-Mifflin.

Stull, Andrew and James Puetz. 1996. Political Science on the Internet: A Student's Guide. New Jersey: Prentice Hall.

\section{Internet Resources and Addresses}

1994 Human Rights Report by Country (State Department). gopher://cyfer.esusda.gov/11/ace/state/hrcr 1996 Proposed Federal Budget. http://gnn.com./gnn/wic/govt.27.html CLA World Fact Book. http://gnn.com./gnn/wic/reFbook.02.html Congressional Quarterly. gopher:/gopher.cqalert.com

International Government Resources Gopher. http:/gnn.com./gnn/wic/govt.45.html

Political Science Resource http://www.keele.ac.uk/depts/po/psr.htm

State Department Travel Wamings and Consular Information Sheets. http://gnn.com./gnn/wic/govt.10.html

Supreme Court Rulings.

http://www.law.cornell.edu.supct/

United Nations Gopher. http:/gnn.com./gnn/wic/govt.29.html

The World Wide Web Virtual Library of State Government.

http://gnn.com./gnn/wic/state.01.html

Yahoo Index of Government by Country. http:/gnn.com./gnn/wic/govt.41.html

\section{Software/Laserdisc/CD-ROM Sources Reviewed/Cited.}

The ' 92 Vote. ABC News Interactive. 1993. System Requirement: IBM PC; 640k RAM; DOS 5.0; VGA, (CD-ROM). American Government: An Introduction Using MicroCase. 3rd. Microcase. 1995.

American Government CD-ROM. Brown \& Benchmark Publishers 1994. Developed by 
Lunaria. System Requirements: IBM PC 386 or higher; 8 MB RAM; 4 MB available Hard Drive; VGA monitor; DOS 3.3; Windows 3.1 and Windows multimedia extensions.

American Government Allyn \& Bacon, 1995. System Requirements: PC: 486 PC, 4 MB RAM, 256 Color, Sound Card, Quick Time 2.0; MAC: 4 MB RAM, 256 Color, Quick Time 2.0, (CD-ROM).

American Government Lecture Launchers. W. W. Norton \& Company, 1994. (Laserdisc). American Government Multimedia Study Guide and American Government Simulation Games. Prentice Hall, 1994. System Requirements: IBM or Macintosh multimedia platforms, (Software).

American Government: Roots and Reforms Videodisc. Allyn and Bacon, 1995.

American Government and Politics Today: 1995-1996 Interactive CD-ROM Edition. West 1995 . Developed by Intellimation. System Requirements: For MAC: IIci; System 7.0; 6MB RAM; 256 color monitor; Quicktime 1.6.2*; Soundmanager 3.0* (*included on CD-ROM), CD-ROM Drive. For IBM: PC 386; 6MB RAM; Super VGA; Quicktime 1.1.1 (included on CD-ROM); Creative Technologies Sound Blaster compatible Sound Card; Windows 3.1.

Capital Hill. Software Toolworks, 1994. System Requirements: IBM PC 386DX/33 $\mathrm{MHz}$ or larger; $1 \mathrm{MB}$ RAM; VESA VBE 1.2 compatible SVGA ( 640 by $480,256-$ color, 512 video memory); color monitor; Sound Blaster or Pro AudioSpectrum sound card or compatible; Windows 3.1 or later, DOS 5.0 or later, MSCDEX 2.21 or later, (CD-ROM).
CD-ROM For American Government. Harcourt Brace, 1996.

Chadwyck-Healy:

House of Commons Hansard on CD-ROM

House of Lords Hansard on CD-ROM

UNBIS Plus

EUROCAT

OJindex $C D$

The Clinton Health Security Plan. Allegro New media, 1994. System Requirements: IBM MPC; Windows 3.1, (CD-ROM).

Clinton: Portrait of Victory. Time-Warner Interactive 1993. System Requirements: IBM PC; 640K RAM; CGA or VGA+ or SVGA card; Sound Blaster, (CD-ROM).

Desert Storm: The War In the Persian Gulf. Time-Warner Interactive 1993. System Requirements: IBM MPC with multimedia extensions; 4MB RAM, (CD-ROM).

Interest Groups and the Power of PACS Level III Videodisc. West 1994.

Hypergrapics CD-ROM. McGraw Hill 1995.

Microcase Explorit: The American Survey. Microcase Corporation, 1996. System Requirements: IBM 286 or compatible, $640 \mathrm{k}$ RAM, MSDOS 3.3 or Windows, VGA level graphics, $1 \mathrm{MB}$ hard drive.

Political Risk Services On CD-ROM. Advanced Multimedia 1994. System Requirements: IBM PC or higher; 2 MB RAM or higher; DOS 3.0 and/or WIN 3.1; CD-ROM extensions.

Politics in Action. Harper Collins 1995, (Laserdisc).

Quanta Publications, (various dates and titles). System Requirements: All of the Quanta products are dual-formatted for MAC and IBM and easily installed and run. IBM users require PC 386 or higher,
512K RAM, MS-DOS 2.0 or higher, and CD-ROM Extensions.

CIA World Fact Book. Quanta, updated 1993.

KGB Fact Book. Quanta 1992.

Middle East Diary. Quanta, 1990.

Terrorist Group Profiles. Quanta, 1991.

U.S. Civics: Federal Citizenship Tests. Quanta, 1993.

Vietnam Remembered. Quanta, 1992.

West's American Government Videodisc. West 1994.

\section{About the Authors}

Carl J. Luna is associate professor of political science, San Diego Mesa College. He holds a $\mathrm{Ph} . \mathrm{D}$. in political science from American University.

Joe Mac McKenzie is professor of political science, San Diego Mesa College. He holds a $\mathrm{Ph} . \mathrm{D}$. in political science from the University of California-Riverside and a J.D. in law from the University of San Diego.

Both have been actively been researching, publishing and presenting at conferences in the field of educational multimedia for the last several years, and recently completed a grant from the state of California to develop and evaluate methods for integrating multimedia more effectively into the curriculum. Luna and McKenzie are also frequent commentators and contributors on political events for local public radio, the San Diego Union, and the McNeil Newshour Online.

\section{Using "Capitol Hill" CD ROM To Teach Undergraduate Political Science Courses}

\section{Cynthia Opheim and W.B. Stouffer, Southwest Texas State University}

\section{An Overview of "Capitol Hill" (Amazing Media, The Software Toolworks, Inc.)}

The CD ROM "Capitol Hill"1 offers an interactive strategy for teaching about Congress in an undergraduate American Government or Legislative Process class. Multiple video sequences and photographs, along with narration, text, and a game, supplement lectures on legislative organization and procedure. The program is presented from the view of a newly elected representative, a soon to be insider. While the version we used introduced leaders and committee chairs from the 103rd Congress, there was more than enough information to encourage students to explore the institution.

The CD is composed of six major components: an extensive glossary, a member's first day in office, orientation for freshman members, a tour of the Capitol, member office and staff, and "Power Play," a game that allows players to advance in the congressional leadership hierarchy as they answer questions correctly. The program also contains sidebar features. Some of these are fun and frivolous such as letters and phone calls from constituents often about inane subjects. The player is periodically asked to vote on real issues, although no in-depth explanation or discussion of these issues is offered. The most valuable sidebars feature remarks and explanations of congressional history, organization, and process given by members of Congress and scholars. For example, Richard Baker, a prominent Senate historian, embellishes the description of the upper chamber's role in treatymaking by describing George Washington's precedent setting actions and the League of Nations debacle.

An important feature of the CD ROM format is that the disks are 